\title{
THE IMPACT OF ROAD ROUGHNESS ON THE DURATION OF CONTACT BETWEEN A VEHICLE WHEEL AND ROAD SURFACE
}

\author{
Vidas Žuraulis, Loreta Levulytė, Edgar Sokolovskij \\ Dept of Automobile Transport, Vilnius Gediminas Technical University, Vilnius, Lithuania
}

Submitted 20 January 2014; resubmitted 7 April 2014; accepted 26 May 2014

\begin{abstract}
The paper analyses the impact of the road micro-profile on the duration and the type of the vehicle wheel contact with the road surface driving at different speed. The selected vehicle bicycle model describes vertical displacements of front and rear wheels and their suspension as well as the impact of the vehicle body motion and longitudinal oscillation. International Roughness Index (IRI) and micro-profile irregularities of the road section analysed in the paper were identified using specialized road testing equipment. The experimental investigations measuring the vehicle suspension displacement and the body acceleration were carried out. Frequency characteristics of suspension motion and regularities of vertical movement of the wheel were identified after dividing the investigated road section according to driving modes. The analysis into the wheel contact with the road surface and identified correlations enable to determine the vehicle stability on selected quality roads.
\end{abstract}

Keywords: road pavement roughness; IRI; suspension displacement; vertical acceleration; wheel motion; contact duration.

\section{Introduction}

The interaction between a vehicle and road pavement can be investigated as the subsystem driver-vehicleroad-environment and as each separate element of this system. The environmental impact, pollution, traffic flows of heavy vehicles and passenger cars have a negative impact on the road and its pavement structure. In the course of time, road pavement deformations and other defects occur, which later weaken the asphalt pavement structure and cause set deformations of the road pavement, which provoke occurrence of road pavement roughness (Sivilevičius, Vansauskas 2013). Road pavement roughness has a negative impact on the vehicle construction and, as a result, on traffic safety (Zaabar, Chatti 2011). Evaluation of road user costs including repair and maintenance costs and cargo damage is performed using vehicle-road interaction models (Zaabar, Chatti 2010).

Road roughness causes a spectrum of oscillations for a moving vehicle and influences the accelerations of sprung and unsprung masses. The power spectral density characteristics of road profile can be estimated using straight line approximation. Probability density function and other calculations of statistical parameters were made to define the road pavement unevenness. Ap- proximation of three unconnected lines has the closest fitting to measured results and $6 \div 14 \%$ of mean error (Múčka 2012a, 2012b).

Vehicle safety is often estimated by calculating contact force between a wheel and road pavement. Coulomb's friction relationship is used to determine that a wheel can't transmit horizontal forces provided the vertical force is null. Scientists analysed a quarter-car vehicle model and its interaction with measured elevation of road pavement. PDS analysis of surface irregularities was used. The vehicle speed limit of $25 \mathrm{~km} / \mathrm{h}$ was determined, starting from which the probability to lose wheel contact started to rise (Barbosa 2011).

Three-dimensional tyre contact stress at various load levels was analysed in order to estimate the influence of road pavement. Increase of the vertical load of the wheel increases the contact stress at tyre edges (Wang, Al-Qadi 2009). In the contact area with road surface, the tyre stress reaches a critical period, which causes the principal material tensile stress on the axis and affects the tyre edge tear (Wang et al. 2011).

The changing vehicle speed and profile of the pavement impacts the frequency of the vehicle mass oscillations, which impacts the driving characteristics, the vehicle braking parameters, which relate directly to traffic safety situation (Sokolovskij, Prentkovskis 2013).

Corresponding author: Edgar Sokolovskij

E-mail: edgar.sokolovskij@vgtu.lt 
The developing technologies require to evaluate vehicle-wheel-road interaction as a whole by identifying its common points and searching for optimal solutions. Equal motion of the vehicle is a quality which describes the comfort for passengers as well as safety for road users and freight (Rouillard 2008). When a vehicle moves on the road pavement with different roughness at a wide range of speed, a lot of various factors impact on characteristics of the vehicle wheel contact (Flintsch et al. 2009; Žuraulis et al. 2013; Sokolovskij et al. 2007; Levulyte et al. 2014) Taking into consideration the forces impacting on the vehicle and how it moves in terms of rutting and asphalt pavement, mathematical models are constructed and applied to analyse the reactions of a vehicle moving on a rough road (Fwa et al. 2012).

The main functions of a shock absorber, as one of the main elements of suspension, are damping road irregularities, ensuring the quality of vehicle steering and the comfort and safety of passengers (Dixon, Mech 2014). Functions and characteristics of shock-absorbers were evaluated and analysed in the paper written by Italian researchers (Arcidiacono et al. 2001). The construction stiffness and damping characteristics will be taken into consideration while modelling active and passive suspensions (Schiehlen et al. 2007; Liberzon et al. 2001).

When a vehicle is moving on a rough road pavement, the excitation of periodical vehicle bounce occurs, which causes the reduction of the wheel adhesion with the road pavement. To evaluate the efficiency of traffic safety, it was proposed to use accident rate coefficient, which takes into account road pavement roughness (Filippov et al. 2009). The paper (Li et al. 2012) presents comprehensive analysis into the impact of road roughness on the vehicle's suspension performance and driving comfort. The excitation of suspension from road roughness is modelled as a stationary process complying with ISO standard requirements on the road roughness. The paper points out that one of the main elements impacting on the power absorbed by chassis when driving on the road pavement irregularities is the tyre and its stiffness properties. The same paper emphasizes that when the driving speed of the vehicle is gradually increased, the vibration impact of the road pavement roughness on the driver is less (Zhang 2010). The vehicle's sprung and unsprung mass vibrations impact on the exploitation properties of chassis, driving characteristics and the vehicle stability. ISO 2631-1:1997 standard is applied for investigations on the vibrations transferred to a human body via contact surfaces. Vibrations caused by mechanical impact occur in vehicles, machines, buildings, etc. Both human health and vehicle construction should avoid resonant frequency oscillations as such cases are dangerous for health and endurance of the structure.

Suspension and tyres protect the vehicle body from dynamic impacts, caused by road pavement irregularities, absorb vibrations and adapt them to the frequency range of a human body. The following trends in the development of the road transport could be pointed out: the increasing number of vehicles, i.e. traffic volumes impact on the improvement of traffic infrastructure, the latest road construction technologies are used for paving roads, newer and more durable materials are used in pavement structures in order to avoid road pavement roughness and various defects as well as to save costs resulting from road maintenance (Čygas et al. 2011; Gintalas et al. 2008; Vislavičius, Sivilevičius 2013).

The analysis of various research works and theoretical literature showed that road pavement roughness has an enormous impact on the general quality of the road, control and exploitation of the vehicle.

This paper provides the analysis of the influence of measured road pavement irregularities on vehicle suspension work in different driving modes and presents the driving speed effect on the suspension displacement and its frequency, and the driving speed influence on the tyre contact duration in the impact with road roughness.

\section{Vehicle and Road Pavement Interaction}

Road pavement roughness is the main parameter which takes into account the general condition of the road pavement and its impact on the road-vehicle system. Random parameters of the road pavement roughness profile cause stochastic vibrations of the vehicle, which could not be described by an unambiguous function. Analysing the vehicle dynamics, the road micro-profile, which includes pavement irregularities of $0.1 \leq$ $\lambda \leq 100 \mathrm{~m}$ wavelength, is taken into account for vertical excitation. Random periodical road irregularities may be described by applying the following sinus formula (Rill 2011):

$$
y=h \sin \left(\frac{2 \pi}{\lambda}\left(\lambda-\frac{\lambda}{2}\right)\right)
$$

where: $\lambda$ - wavelength of road pavement irregularities; $h$ - height of road roughness.

To evaluate the road surface, expressions of variance and correlation functions are employed (Rill 2006, Bogdevičius 2012):

$$
\begin{aligned}
& \sigma^{2}=\lim _{L_{z} \rightarrow 0} \frac{1}{L_{z}} \int_{0}^{L_{z}} z_{0}^{2}(x) d x ; \\
& R(\xi)=\underbrace{\lim _{y \rightarrow \infty}}_{\substack{x \rightarrow \infty \\
y \rightarrow \infty}} \frac{1}{4 x y} \int_{-x-y}^{x} \int_{-y}^{y} z(x, y) z(x+\xi, y) d x d y,
\end{aligned}
$$

where: $L_{z}$ - length of the road section under investigation; $z_{0}$ - ordinate of road roughness; $y$ - variables (correlating) items; $\xi$ - linear transformation of independent number sequence.

Two-dimensional function (3) is evaluated by horizontal road profile plane according to coordinates $x$ and $y$.

International Roughness Index (IRI) shows the spectrum of height of road irregularities per one metre or kilometre per length of the measured road section. IRI is expressed by a vertical summative displacement of a standard vehicle suspension driving at the speed of $80 \mathrm{~km} / \mathrm{h}$ and the ratio of the travelled distance. Mathematically, IRI is calculated as follows (ASTM E1926-08): 


$$
\text { IRI }=\frac{1}{L} \int_{0}^{L / v}\left|\dot{z}_{2}-\dot{z}_{1}\right| d t
$$

where: $L$ - length of the road section; $v$ - vehicle driving speed; $\dot{z}_{1}$ and $\dot{z}_{2}$ - vehicle sprung and unsprung mass movement velocities, respectively; $\Delta t$ - time interval.

Analysis of the influence made by simulation speed on the variation of IRI value was performed (Perera, Kohn 2004). For simulation speed less than $80 \mathrm{~km} / \mathrm{h}$, identified IRI values showed wider scatter than for greater simulation speed. In general, IRI varies from 0.4 up to $0.6 \mathrm{~m} / \mathrm{km}$. Analysis also confirmed that $80 \mathrm{~km} / \mathrm{h}$ speed is the most suitable for various pavement types.

The relationships between the IRI and five different straightedge index types of asphalt-concrete and cement-concrete were estimated by regression analysis. The fitting variation of $R^{2} \sim 0.65 \div 0.95$ was defined (Mučka 2012a, 2012b).

Analysing the impact of road irregularities on the vehicle dynamic characteristics, the bicycle model with four degrees of freedom was used (Fig. 1). Bicycle model allows to analyse pitch motion of the vehicle's body in acceleration mode. In addition, the selected model combines unsprung masses to common body, giving the possibility to analyse more natural dynamic system and the influence of different axis motion. Movement along the vertical axis $z$ and body pitch motion $\theta$ of sprung mass are not restricted in this model. Unsprung masses falling on the front and rear axles are also free to move along the vertical axis, $z_{f}$ and $z_{r}$, respectively. The vehicle mass motion is impacted by the road pavement roughness parameters $z_{o f}$ and $z_{o r}$ for front and rear wheels, respectively. Tyre damping is not included because its value is relatively low and has little impact.

The vehicle bicycle model at kinematic excitation from road roughness $z_{0}$, is described by the following equations of motion (Jazar 2008):

$$
\begin{aligned}
& m \ddot{z}+c_{f}\left(\dot{z}-\dot{z}_{f}-a \dot{\theta}\right)+c_{r}\left(\dot{z}-\dot{z}_{r}+b \dot{\theta}\right)+ \\
& k_{f}\left(z-z_{f}-a \theta\right)+k_{r}\left(z-z_{r}+b \theta\right)=0 ; \\
& m_{f} \ddot{z}_{f}-c_{f}\left(\dot{z}-\dot{z}_{f}-a \dot{\theta}\right)- \\
& k_{f}\left(z-z_{f}-a \theta\right)+k_{f}^{\prime}\left(z_{f}-z_{0 f}\right)=0 ; \\
& m_{r} \ddot{z}_{r}-c_{r}\left(\dot{z}-\dot{z}_{r}+b \dot{\theta}\right)- \\
& k_{r}\left(z-z_{f}+b \theta\right)+k_{r}^{\prime}\left(z_{r}-z_{0 r}\right)=0 ; \\
& I_{y} \ddot{\theta}-a c_{f}\left(\dot{z}-\dot{z}_{f}-a \dot{\theta}\right)+b c_{r}\left(\dot{z}-\dot{z}_{r}+b \dot{\theta}\right)- \\
& a k_{f}\left(z-z_{f}-a \dot{\theta}\right)+b k_{r}\left(z-z_{r}+b \theta\right)=0,
\end{aligned}
$$

where: $m_{f}, m_{r}$ - masses of front and rear axles, respectively; $z$ - body vertical displacement; $z_{f}, z_{r}$ - wheel vertical displacement of front and rear axles; $z_{0 f}, z_{0 r}-$ road roughness effect for front and rear axles wheel; $k_{f}$, $k_{r}$ - front and rear suspension stiffness coefficients; $c_{f}$, $c_{r}$ - front and rear suspension damping coefficients; $k_{f}^{\prime}$, $k_{r}^{\prime}$ - front and rear tyres stiffness coefficient; $\theta$ - body pitch motion; $I_{y}$ - body lateral mass moment of inertia.

The bicycle model provides a possibility to evaluate the generalized motion of the front and rear axles of the vehicle without taking into account the regularities

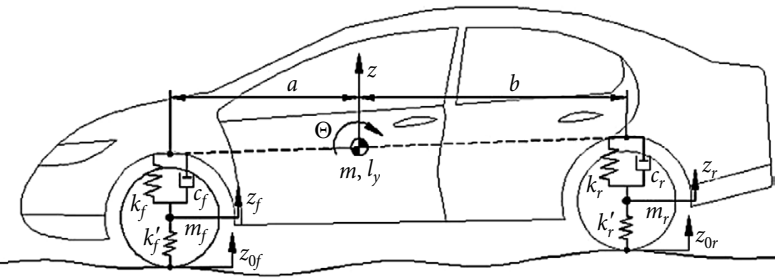

Fig. 1. Vehicle bicycle model

of the individual motion of each wheel. It is a very convenient method to analyse the general vertical displacement of the body and pitch motion, which is caused by displacement of separate axles due to the road surface micro-profile.

Pitch motion occurs due to differences between the vertical motion of the front and rear suspension of the vehicle. It also depends on the vehicle wheelbase, suspension stiffness and damping characteristics, the height of road irregularities and longitudinal road grade. Pitch rate is extremely important investigating the vehicle acceleration and braking as well as driving on road irregularities. Oscillations around the pitch occur due to different moments when front and rear wheels of the vehicle drive on road irregularities (depending on the driving speed and the wheelbase).

It is identified, that average own frequency oscillations of suspension is approx. $1.4 \mathrm{~Hz}$ (Smith et al. 2010). Based on the data of experimental driving with suspension motion characteristics, the change of oscillation frequency is expressed as follows (Rill 2011):

$$
f=\frac{\Delta \dot{z}_{i}}{2 \pi \Delta z_{i}},
$$

where: $\Delta \dot{z}_{i}$ - suspension motion speed; $\Delta z_{i}$ - suspension motion amplitude. Suspension motion amplitude may be divided as follows (Dixon, Mech 2014):

$$
\Delta \dot{z}_{i}=A \sin \omega t+B \cos \omega t,
$$

where: $\omega$ - frequency of suspension motion angular oscillation. Values $A$ and $B$ :

$$
A=z_{i} \cos \phi ; B=z_{i} \sin \phi,
$$

where: $\phi$ - shift angle of curves.

When a wheel jumps over the road depression, its momentary vertical force to road pavement increases at every nearest irregularity (Fig. 2).

Depending on vertical stiffness characteristics of a tyre, the wheel absorbs part of minor road irregularities.

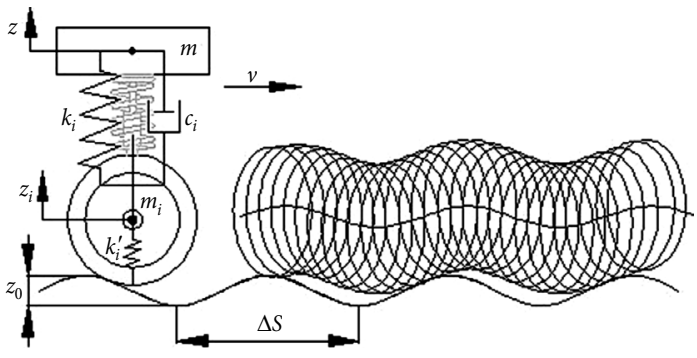

Fig. 2. Wheel model and trajectory by jumping over road irregularities 
Vertical load, which impacts on the static deflection of the tyre on the wheel due to its periodic oscillation is expressed as follows (Jazar 2008):

$$
F_{z}=F_{z 0}+\Delta F_{z}=F_{z 0}+F_{z}^{\prime} \sin 2 \pi \frac{s}{\lambda},
$$

where: $F_{z 0}$ - vertical wheel load; $\Delta F_{z}$ - variable part of load; $F_{z}^{\prime}$ - amplitude of variable load; $s$ - travelled distance; $\lambda$ - wavelength of load oscillation.

The property of the tyre evenly rolling on the road irregularities can be characterized by relative damping, which depends on the driving speed (Pacejka 2005):

$$
c_{t}^{\prime}=\frac{1}{2} \frac{I_{w} v}{c_{t} r_{0}^{2}} \omega_{\Omega 0},
$$

where: $I_{w}$ - wheel moment of inertia; $v$-driving speed; $c_{t}$ - tyre damping coefficient; $r_{0}$ - effective wheel radius, $\omega_{\Omega 0}$ - angular oscillation frequency of the wheel.

Eq. (13) shows that vehicle acceleration causes stronger damping of the tyre.

The relation between wheel bounces, at different speed, and road roughness can be statistically evaluated by correlation functions (Rill 2011). The correlation analysis can also be used for comparison of the suspension vertical motions (displacement) at different driving speed. The analytical formulations are proposed for cases, when initial results do not present satisfactory correlation with measured values, obtaining improved analytical solutions capable of reproducing real vehicle results with good accuracy.

\section{Methodology and Equipment of Experimental Investigations}

Gauging of road pavement irregularities is achieved by either visual inspections or using an instrumented vehicle that can take physical measurements. Only a limited number of the latter are available. The mobile road survey laboratory (RST 28), which is produced by Ramböll RST (http://rst.ramboll.se), was used (Fig. 3a) too identify the parameters of the road section under investigation. This laboratory measures road pavement parameters and pavement surface defects.

Mobile road survey laboratory RST 28 is mounted on the base of Mercedes-Benz Sprinter and has:
- a gyroscope, which measures longitudinal and crosswise road pavement profile;

- laser meters, which measure longitudinal and crosswise road micro-profile (laser profilograph);

- a distance sensor;

- a camera, which detects pavement defects;

- accelerometers, which isolate internal vibrations of measuring equipment affecting on the indicators of laser meters;

- a processor, which processes data from all sensors;

- a computer, which controls processor's work and stores data.

Using the laser technology, a detailed image of the road pavement surface is reproduced on the computer screen. When the vehicle is driving on the road pavement irregularities, its unsprung and sprung masses have different motion as the wheel directly interacts with the road pavement. Shock absorbers and springs, having absorbed part of mechanical power generated from road pavement irregularities, transfer displacements to sprung masses. Wheel-road interaction is transmitted to the vehicle suspension and during this transmission, the computer algorithm forms the IRI value.

The equipment for measuring dynamic parameters of the vehicle was used to identify the impact of road pavement roughness on the vehicle's driving characteristics. The accelerations and rotation speed acquired by the vehicle body were measured by triaxial sensor Corrsys-Datron Multi-Axial Navigation Systems mounted on the vehicle's sprung masses (Fig. 3b). To measure displacements of sprung and unsprung masses, motion sensors Kubler were mounted on fixing zones of shock absorbers. The mounting scheme is presented in Fig. 3c. Signals from sensors are collected and synchronized on a general scale of time by data acquisition and evaluation system Corrsys-Datron DAS-3 with frequency of $100 \mathrm{~Hz}$.

A light vehicle Toyota Avensis was selected for dynamic testing. The vehicle masses falling on front and rear axles were $820 \mathrm{~kg}$ and $600 \mathrm{~kg}$, respectively; the wheelbase $2.630 \mathrm{~mm}$, summer tyres: 195/60 R15 88H. To identify the regularities of separate vehicle mass motion on the selected road section of $700 \mathrm{~m}$ in length, driving speed of $50 \mathrm{~km} / \mathrm{h}$ and $80 \mathrm{~km} / \mathrm{h}$ were chosen. a)

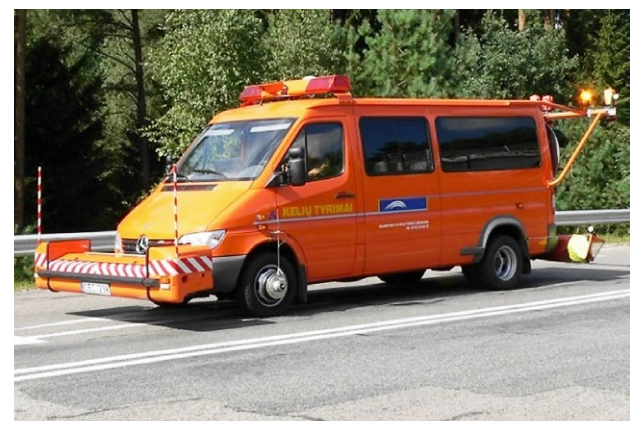

b)

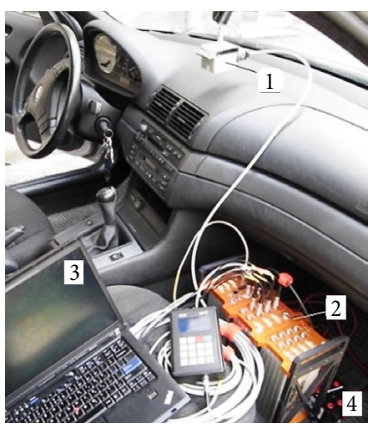

c)

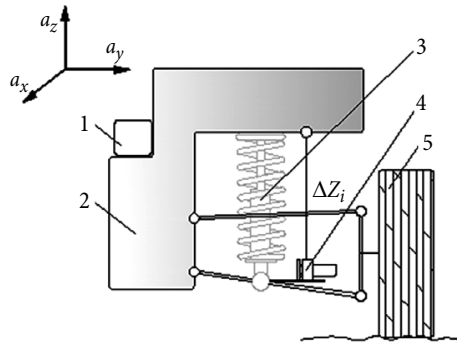

Fig. 3. Equipment used during experimental tests: a - mobile road survey laboratory RST 28;

b - equipment inside the vehicle: 1 - acceleration sensor, 2 - data acquisition system, 3 - computer, 4 - battery;

c - scheme for measurement of vehicle dynamical parameters: 1 - 3-axial accelerometer and gyroscope sensor,

2 - sprung mass, 3 - shock absorber and spring, 4 - potentiometer sensor for measuring linear motions, 5 - unsprung mass 


\section{Experiment Data}

The values of road roughness, which were collected by the mobile road survey laboratory RST 28 (Fig. 4), were analysed. The IRI in the measured road pavement was calculated using Eq. (4) and amounted to $1.412 \mathrm{~m} / \mathrm{km}$.

The data enable to forecast the impact of the road pavement roughness on the motion of the vehicle; therefore, comparing the measured dynamic driving parameters of the vehicle on a certain road section, typical motion cases were identified. Almost on the entire selected road section, the height of road pavement irregularities varies within the range of -5 to $15 \mathrm{~mm}$. Only in a few cases, higher irregularities were identified. The most significant irregularities were identified on the road section between the 450 and $480 \mathrm{~m}$. Here, the road surface irregularities increased up to $35 \mathrm{~mm}$ (Fig. 4). This is evidently demonstrated by further characteristics of displacement of vehicle masses. Since it is a generalized road surface quality parameter showing road irregularities in metre per one kilometre of road, this characteris- tic does not fully simulate the curve of road irregularities although the mentioned more significant irregularities stand out as well.

The used vehicle testing equipment enables to analyse the change of suspension motion and vertical sprung mass acceleration (Figs 5, 6). These parameters characterize best the impact of road pavement irregularities on the vehicle.

According to driving modes and the impact of road irregularities, it is expedient to divide the selected road section under investigation into sub-sections (Table).

\section{Primary Analysis}

During vehicle acceleration (road section S1), the motion of front and rear suspension is mostly impacted by longitudinal acceleration acting on the body, and the impact of the road surface is extremely insignificant. Traction force generated by the engine in tyre-road surface interaction and unevenness of thrust due to mechanical gear switching cause intensive body pitch motion. The

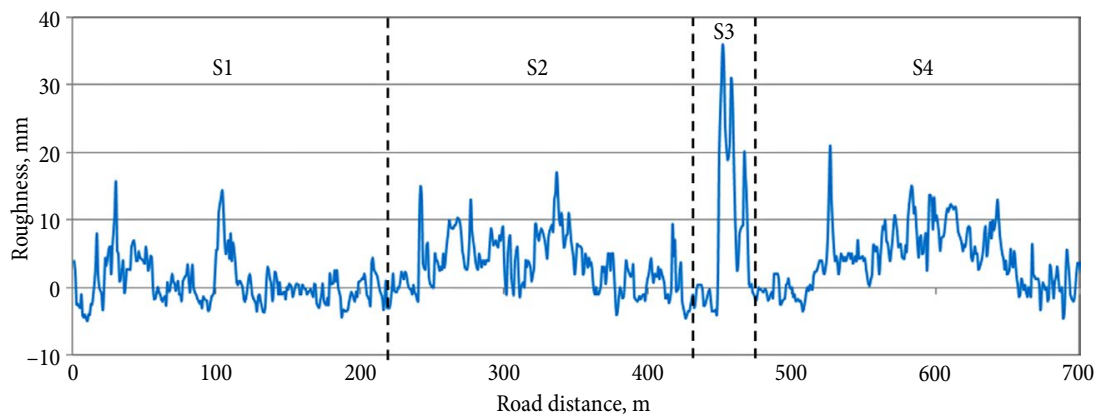

Fig. 4. The road roughness (height of road irregularities) of the selected road section

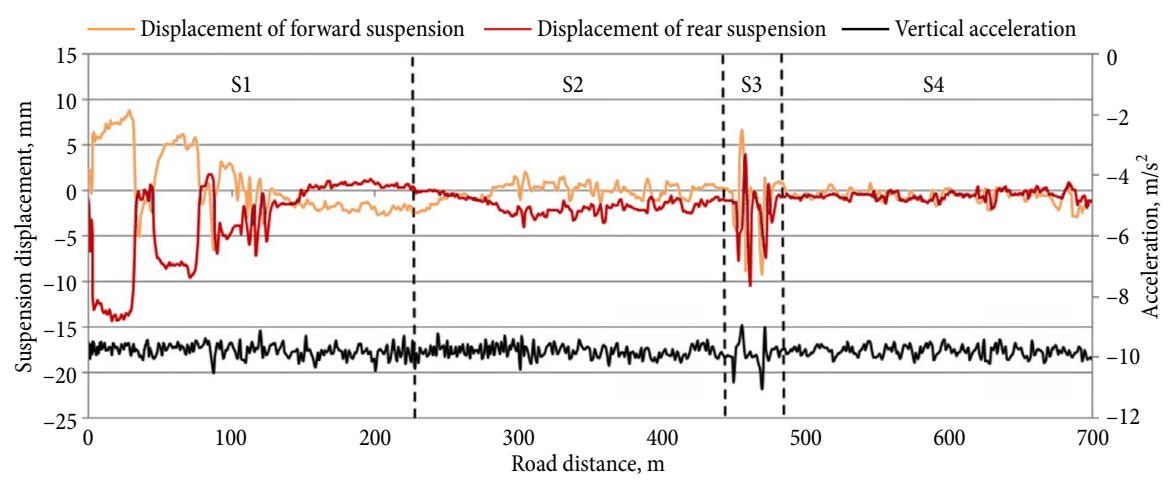

Fig. 5. Vehicle motions in vertical axis, $v=50 \mathrm{~km} / \mathrm{h}$

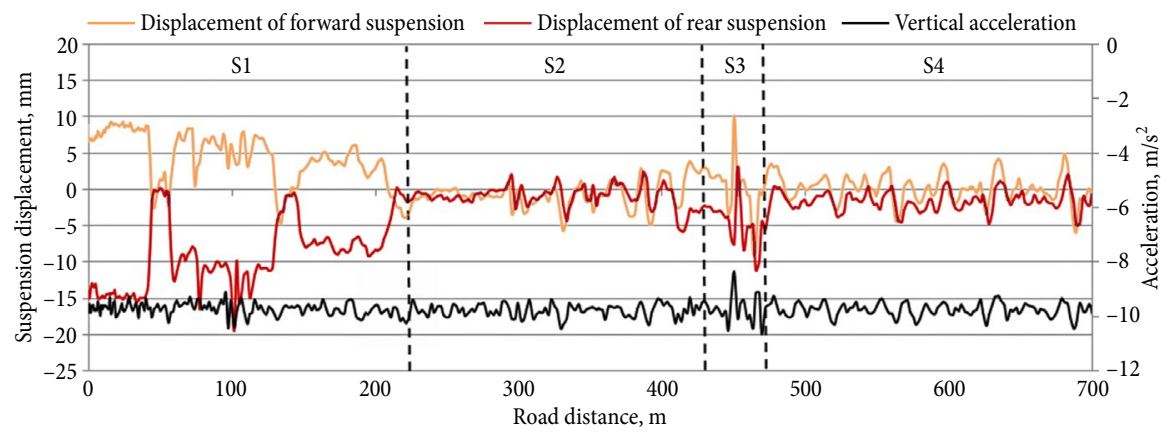

Fig. 6. Vehicle motions in vertical axis, $v=80 \mathrm{~km} / \mathrm{h}$ 
Table. Distribution of selected road

\begin{tabular}{lcc}
\hline Road section, distance & $\begin{array}{c}\text { Longitudinal } \\
\text { acceleration } \\
{\left[\mathrm{m} / \mathrm{s}^{2}\right]}\end{array}$ & $\begin{array}{c}\text { Road } \\
\text { pavement } \\
\text { roughness } \\
{[\mathrm{mm}]}\end{array}$ \\
\hline $\mathrm{S} 1 \quad \begin{array}{l}\text { acceleration, } \\
0 \div 220 \mathrm{~m}\end{array}$ & $a_{x} \geq 1$ & $-10<z_{0}<20$ \\
\cline { 1 - 1 } $\mathrm{S} 2 \begin{array}{l}\text { equal driving, } \\
220 \div 450 \mathrm{~m}\end{array}$ & $-1<a_{x}<1$ & $-5<z_{0}<40$ \\
\cline { 1 - 1 } $\mathrm{S} 3 \begin{array}{l}\text { driving on random road } \\
\text { roughness, } 450 \div 480 \mathrm{~m}\end{array}$ & & $-10<z_{0}<20$ \\
\cline { 1 - 1 } $\mathrm{S} 4 \begin{array}{l}\text { equal driving, } \\
480 \div 700 \mathrm{~m}\end{array}$ & & \\
& &
\end{tabular}

only impact of road roughness at $100 \mathrm{~m}$ is observed in the oscillations of suspension and body. When the vehicle accelerates, the tyre contact surface acts more intensively, front and rear layers are impacted differently; moreover, depending on the driving speed, effective wheel radius changes as well. Thus, at minimal road surface irregularities (at the depth of $10 \mathrm{~mm}$ ), deflections of tyre may exceed the existing irregularities.

Fig. 7 shows frequency characteristics of suspension motion obtained during testing at different driving modes. Narrow frequency range is impacted by the frequency of measuring equipment and the length of the road section under investigation. The obtained characteristic was identified according to the recurrence of suspension motion values registered according to each measurement moment on the road section under investigation.

During equal driving mode (sections S2 and S4), when the driving speed increases up to $80 \mathrm{~km} / \mathrm{h}$, the oscillation amplitudes of front and rear suspension motions and sprung mass vertical acceleration increase. It is especially obvious on the second road section of equal driving (S4). One of the evaluation methods of random vibrations is standard deviation of a data sample, which is equal to square root divided by dispersion (Eq. (2)). The estimated standard deviation of equal driving at the speed of $50 \mathrm{~km} / \mathrm{h}$ on a rather even road is 2.81 . Driving under the same conditions at the speed of $80 \mathrm{~km} / \mathrm{h}$, the standard deviation is 4.56 . When the driving speed is higher, suspension motion distribution would start reducing as the wheel would keep jumping over more and more road irregularities and would straighten its movement trajectory. The highest suspension motions obtained at the vehicle acceleration mode on average make up $12 \mathrm{~mm}$. However, the frequency band at this mode is the narrowest as it is only a primary unstable stage of driving. At equal driving, when the driving speed is $50 \mathrm{~km} / \mathrm{h}$ and $80 \mathrm{~km} / \mathrm{h}$ (Figs 5,6 , S2 and S4 sections), the displacement of suspension moves the least and the frequency increases only at minimal (up to 1 $\mathrm{mm}$ ) motions. In the frequency dependence of suspension motion, the frequency range of S3 curves (Fig. 7), which show driving on significant road irregularities, is the widest although the driving duration at this mode is the shortest.

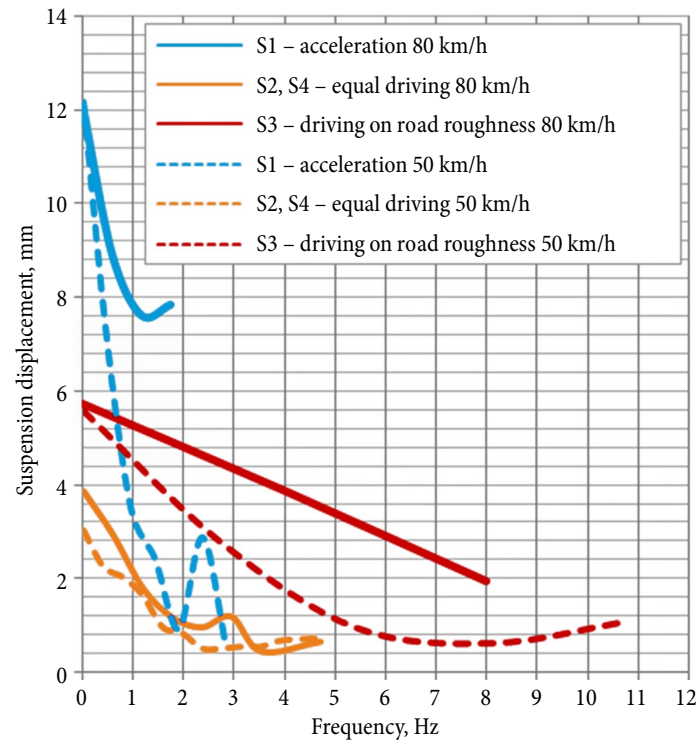

Fig. 7. Frequency characteristics of the vehicle suspension motion at different driving modes

Intensive road surface irregularities vary by up to $30 \mathrm{~Hz}$, suspension natural frequency including tyre damping and stiffness could reach $10 \div 15 \mathrm{~Hz}$ (Heißing, Ersoy 2011). Therefore, it could be stated that wheels on these intensive irregularities move unevenly. Tyre's tread block strikes against the rough roughness and deforms; however, due to the hysteresis effect, it does not immediately revert to its initial shape on the other side of the rough spot. This asymmetrical deformation generates a force field and stiffness, and damping elements cannot react fast enough to concentrate the vertical force and to keep adhesion.

Passengers feel a discomfort because of the influence of road roughness on the vertical acceleration of the vehicle body. According to ISO 2631-1:1997, people are most sensitive to vertical frequency of approx. $4 \div 8 \mathrm{~Hz}$ and to the lateral frequency or approx. $1 \div 2 \mathrm{~Hz}$. The area of vertical acceleration of the vehicle body, which causes the discomfort for passengers, is shown in section S3 (Figs 5, 6).

When the speed is increased at all driving modes due to the increased suspension motion amplitude and increased sprung mass vertical acceleration amplitudes, it could be preliminary stated that the wheel movement trajectory changes. The wheel does not repeat road surface irregularities and for a certain time does not contact with the road surface. It is extremely dangerous at low road pavement adhesion conditions, moving on a turn or under a very strong lateral wind. In such a case, when a wheel does not manage to repeat the road profile accurately and a part of the road is just jumped over, stability may be lost. The capability of the wheel to repeat road irregularities is directly impacted by the reaction speed of a shock absorber, i.e. under the existing loading conditions to press the wheel as soon as possible without losing contact. This characteristic directly depends on external conditions, i.e. road roughness. 


\section{Evaluation of Wheel Contact}

Analysing the case of vertical wheel excitation, which occurs due to the road roughness in section S3 (Fig. 4), suspension and unsprung mass vertical motion $\left(z_{0 i}\right)$ are compared at different speed. In case of significant road irregularities (section S3) and the driving speed of 50 $\mathrm{km} / \mathrm{h}$, suspension motions of front and rear axles reach $15 \mathrm{~mm}$. When the speed is increased up to $80 \mathrm{~km} / \mathrm{h}$, the front axle suspension motion increases by $3 \mathrm{~mm}$, and that of the rear one does not change. Assuming that period $T$ is equal to the ratio of travelled distance $\Delta S$ and vehicle velocity $v$, angular oscillation frequency is written as follows:

$$
\omega=\frac{2 \pi}{T}=\frac{2 \pi v}{\Delta S},
$$

then the wheel vertical motion corresponding to the excitation due to road irregularities equals to:

$$
z_{i}=Z \sin \omega t=\frac{\left(\Delta z_{i}-\Delta z\right)}{2} \sin \frac{2 \pi v}{\Delta S} \Delta t
$$

where: $Z$ - curve oscillation amplitude; $z_{i}$ - wheel vertical motion; $\Delta z_{i}$ - suspension displacement change per $\Delta t ; \Delta z$ - body vertical motion change per $\Delta t ; \Delta S-$ travelled distance per $\Delta t ; \Delta t$ - time interval.

The body vertical motion:

$$
z=\iint_{t} a_{z} d t
$$

where: $a_{z}$ - body vertical acceleration.

The exact wheel motion is identified by Eq. (15), where body vertical displacements are also taken into account. Road irregularities also impact on the suspension motion, and cause longitudinal oscillations, which affect the operation of front and rear suspensions differently (see chapter 1 ).

Fig. 8 presents vertical motion of the wheel calculated according to Eq. (15) when driving on road roughness on section $S 3$. When driving at the speed of $50 \mathrm{~km} / \mathrm{h}$, the wheel manages to repeat road irregularities. It could be observed by its motion upwards and

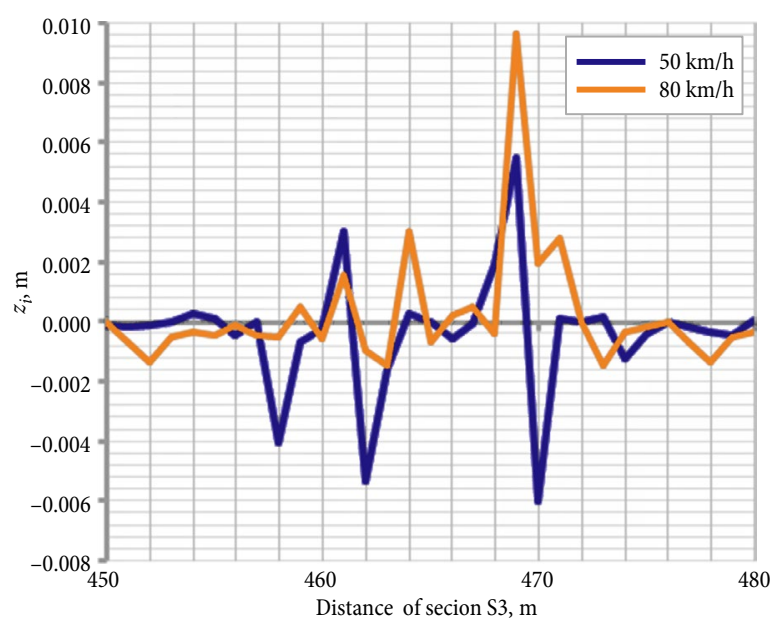

Fig. 8. Wheel motion when driving on road roughness at different speed downwards. Driving at the speed of $80 \mathrm{~km} / \mathrm{h}$, road irregularities are missed and upper peaks of the motion start increasing. This phenomenon is explained by wheel bouncing onto road roughness.

Statistical correlations between a random process of wheel/tyre contact force with road roughness were calculated from the measurement data described in chapter 3. Driving at the speed of $50 \mathrm{~km} / \mathrm{h}$ and 80 $\mathrm{km} / \mathrm{h}$ according to determined wheel vertical motions on the road irregularity of $30 \mathrm{~mm}$ (Fig. 8), the correlation coefficient of 0.464 was calculated. It denotes a weak correlation of the wheel motion when driving at the speed of 50 and $80 \mathrm{~km} / \mathrm{h}$. However, when correlation analysis on equal driving (S2 and S4) was conducted, this relationship was even weaker (0.217), and in acceleration mode (S1) this relationship became extremely insignificantly negative $(-0.075)$. Due to different driving speed and working characteristics of the tyre and the suspension, strong correlation is not expected, and the strongest correlation identified in mode S3 shows that only a significant road irregularity forces the wheel to repeat the road surface. In other driving modes, in the range of velocities between $50 \div 80 \mathrm{~km} / \mathrm{h}$ on a rather even asphalt concrete road pavement $(1.0<I R I<2.0 \mathrm{~m} / \mathrm{km})$, no exact relationship between the wheel's vertical motion and the road roughness is identified. Therefore, up to $10 \mathrm{~mm}$ road irregularities are absorbed by the system tyre-suspension unevenly; however, without causing any danger to the vehicle's stability.

Searching for momentary losses of the wheel contact with the road surface on a rather even road, compared with the wheel radius, vertical tyre dynamics will be evaluated as well. The value of the wheel motion, when it loses contact with the road surface, depends on the stiffness of the tyre. To find out the moments then tyre losses contact, the critical value is estimated:

$$
z_{i}=\frac{F_{v}}{k_{t}},
$$

where: $z_{i}$ - wheel vertical motion; $F_{v}$ - vertical force acting on the wheel; $k_{t}$ - tyre stiffness coefficient.

When the determined wheel motion upwards exceeds vertical deflection of the tyre, the contact with the road is lost. When evaluating momentary losses of the wheel contact with the road surface in vitro at equal driving, it was identified that when the driving speed is $50 \mathrm{~km} / \mathrm{h}$, the wheel does not contact directly with the road $4.64 \%$ of the driving duration. When the speed increases up to $80 \mathrm{~km} / \mathrm{h}$, it increases by $6.93 \%$.

Determined losses of wheel contact duration have no significant impact on vehicle stability at equal driving, but could cause extreme situation on curved driving trajectories or places where the risk of side wind gusts appears. Traffic management including speed restrictions and installation of warning signs should be selected not only depending on road curvature and traffic environment, but also considering road pavement roughness. 


\section{Conclusions}

As the study demonstrates, measurement results pertaining to the micro-profile (pavement irregularities) of the road can help to rather accurately predict the interaction (correlation) between a vehicle dynamics parameters, such as suspension displacement, wheel motion, and a road pavement irregularities. The advantage of this approach is the possibility to analyse vehicle dynamic response subjected to real description of pavement irregularity. Results allow us to quantify passenger comfort and tune suspension parameters of the plain view of the pavement irregularities.

During vehicle acceleration, the impact of road irregularities on the motion of the vehicle sprung and unsprung masses are observed only in case of $10 \mathrm{~mm}$ road irregularities. Suspension motion at acceleration mode is excited by longitudinal acceleration and road irregularities, first of all, impact on the longitudinal slip characteristics of tyres, which under the influence of external forces, may result in the loss of the vehicle stability.

At equal driving, when suspension motion oscillations are compared and the speed increases from 50 to $80 \mathrm{~km} / \mathrm{h}, 1.6$ times higher distribution of suspension displacement values was observed. It shows that momentary normal reactions of the vehicle wheel increase when the speed is increased and when a part of road irregularities are jumped over with the wheel bouncing over to the next irregularity.

Driving on the road irregularity higher than 30 $\mathrm{mm}$, which stands out in the general spectrum of irregularities, and taking into consideration vertical suspension motion and sprung mass displacement, it was identified how the wheel movement trajectory changes. Driving at the speed of $80 \mathrm{~km} / \mathrm{h}$, the wheel motion increases in vertical direction, however, only upwards. Skipping upper zones of motion, the wheel does not contact with the road surface for a certain moment of movement on the road irregularity. When the driving speed is $80 \mathrm{~km} / \mathrm{h}$, it may take up to $6.93 \%$ of the driving time. When the vehicle is influenced by lateral forces or low friction road pavement, such losses of tyre contact tyre may significantly impact on the general stability of the vehicle.

To achieve better adhesion of the wheel with road surfaces of various grading, a shock absorber as the main structural element of suspension of pressing the wheel to the road surface should have well-balanced stiffness and damping characteristics, so that the wheel rolling on road irregularities at various speed contacted the road surface faster. The height of the tyre profile and stiffness characteristics should guarantee handling of small up to $10 \mathrm{~mm}$ road irregularities without losing contact.

\section{References}

Arcidiacono, G.; Capitani, R.; Vianello, M. 2001. Simulated experimental design used to define the characteristic curves of car shock-absorbers, Quality and Reliability Engineering International 17(2): 71-84.

http://dx.doi.org/10.1002/qre.383
ASTM E1926-08. Standard Practice for Computing International Roughness Index of Roads from Longitudinal Profile Measurements.

Barbosa, R. S. 2011. Vehicle dynamic safety in measured rough pavement, Journal of Transportation Engineering 137(5): 305-310. http://dx.doi.org/10.1061/(ASCE)TE.1943-5436.0000216

Bogdevičius, M. 2012. Transporto priemoniu dinamika: Mokomoji knyga. Vilnius: Technika. 205 p. (in Lithuanian).

Čygas, D.; Mučinis, D.; Sivilevičius, H.; Abukauskas, N. 2011. Dependence of the recycled asphalt mixture physical and mechanical properties on the grade and amount of rejuvenating bitumen, The Baltic Journal of Road and Bridge Engineering 6(2): 124-134. http://dx.doi.org/10.3846/bjrbe.2011.17

Dixon, J. C.; Mech, F. I. 2014. The Shock Absorber Handbook. Society of Automotive Engineers Inc. 495 p.

Filippov, V. V.; Smirnova, N. V.; Kiyashko, D. I. 2009. Otsenka vliyaniya nerovnostey dorozhnykh pokrytiy na bezopasnost dvizheniya, Vestnik Kharkovskogo Natsionalnogo Avtomobil'no-Dorozhnogo Universiteta 47: 63-65. (in Russian).

Flintsch, G. W.; Izeppi, E. L.; McGhee, K. K.; Roa, J. A. 2009. Evaluation of international friction index coefficients for various devices, Transportation Research Record 2094: 136143. http://dx.doi.org/10.3141/2094-15

Fwa, T. F.; Pasindu, H. R.; Ong, G. P. 2012. Critical rut depth for pavement maintenance based on vehicle skidding and hydroplaning consideration, Journal of Transportation Engineering 138(4): 423-429.

http://dx.doi.org/10.1061/(ASCE)TE.1943-5436.0000336

Gintalas, V.; Žilioliené, D.; Dimaitis, M.; Lukošaitis, D.; Lipnevičiūtè, K.; Vitkienè, J. 2008. Analysis of design solutions in the objects of gravel roads paving programme in terms of traffic safety, The Baltic Journal of Road and Bridge Engineering 3(2): 93-100.

http://dx.doi.org/10.3846/1822-427X.2008.3.93-100

Heißing, B.; Ersoy, M. 2011. Chassis Handbook: Fundamentals, Driving Dynamics, Components, Mechatronics, Perspectives. Vieweg+Teubner Verlag. 591 p.

http://dx.doi.org/10.1007/978-3-8348-9789-3

ISO 2631-1:1997. Mechanical Vibration and Shock. Evaluation of Human Exposure to Whole-Body Vibration. Part 1: General Requirements.

Jazar, R. N. 2008. Vehicle Dynamics: Theory and Application. Springer-Verlag US. $1066 \mathrm{p}$. http://dx.doi.org/10.1007/978-0-387-74244-1

Levulytė, L.; Žuraulis, V.; Sokolovskij, E. 2014. The research of dynamic characteristics of a vehicle driving over road roughness, Eksploatacja i Niezawodność - Maintenance and Reliability 16(4): 518-525

Li, Y.; Zuo, S.; Lei, L.; Yang, X.; Wu, X. 2012. Analysis of impact factors of tire wear, Journal of Vibration and Control 18(6): 833-840. http://dx.doi.org/10.1177/1077546311411756

Liberzon, A.; Rubinstein, D.; Gutman, P. O. 2001. Active suspension for single wheel station of off-road track vehicle, International Journal of Robust and Nonlinear Control 11(10): 977-999. http://dx.doi.org/10.1002/rnc.636

Múčka, P. 2012a. Longitudinal road profile spectrum approximation by split straight lines, Journal of Transportation Engineering 138(2): 243-251.

http://dx.doi.org/10.1061/(ASCE)TE.1943-5436.0000314

Múčka, P. 2012b. Relationship between international roughness index and straightedge index, Journal of Transportation Engineering 138(9): 1099-1112.

http://dx.doi.org/10.1061/(ASCE)TE.1943-5436.0000417 
Pacejka, H. B. 2005. Spin: camber and turning, Vehicle System Dynamics 43(Supp. 1): 3-17. http://dx.doi.org/10.1080/00423110500140013

Perera, R.; Kohn, S. 2004. Effects of variation in quarter-car simulation speed on international roughness index algorithm, Transportation Research Record 1889: 144-151. http://dx.doi.org/10.3141/1889-16

Rill, G. 2011. Road Vehicle Dynamics: Fundamentals and Modeling. CRC Press. 361 p.

Rill, G. 2006. First order tire dynamics, in III European Conference on Computational Mechanics: Solids, Structures and Coupled Problems in Engineering: Book of Abstracts, 5-8 June 2006, Lisbon, Portugal, 776-776. http://dx.doi.org/10.1007/1-4020-5370-3_776

Rouillard, V. 2008. Generating road vibration test schedules from pavement profiles for packaging optimization, Packaging Technology and Science 21(8): 501-514. http://dx.doi.org/10.1002/pts.840

Schiehlen, W.; Fehr, J.; Jung, K. Y. 2007. Covariance analysis for active vehicle suspensions, PAMM - Proceedings in Applied Mathematics and Mechanics 7(1): 4120001-4120002. http://dx.doi.org/10.1002/pamm.200700260

Sivilevičius H.; Vansauskas, V. 2013. Research and evaluation of ruts in the asphalt pavement on Lithuanian highways, Journal of Civil Engineering and Management 19(5): 609621. http://dx.doi.org/10.3846/13923730.2013.817481

Smith, W. A.; Zhang, N.; Jeyakumaran, J. 2010. Hydraulically interconnected vehicle suspension: theoretical and experimental ride analysis, Vehicle System Dynamics 48(1): 41-64. http://dx.doi.org/10.1080/00423110903243190

Sokolovskij, E.; Prentkovskis, O. 2013. Investigating traffic accidents: the interaction between a motor vehicle and a pedestrian, Transport 28(3): 302-312. http://dx.doi.org/10.3846/16484142.2013.831771

Sokolovskij, E.; Prentkovskis, O.; Pečeliūnas, R.; KinderytèPoškienè, J. 2007. Investigation of automobile wheel impact on the road border, The Baltic Journal of Road and Bridge Engineering 2(3): 119-123.

Vislavičius, V; Sivilevičius, H. 2013. Effect of reclaimed asphalt pavement gradation variation on the homogeneity of recycled hot-mix asphalt, Archives of Civil and Mechanical Engineering 13(3): 345-353. http://dx.doi.org/10.1016/j.acme.2013.03.003

Wang, G.; Roque, R.; Morian, D. 2011. Evaluation of near-surface stress states in asphalt concrete pavement, Transportation Research Record 2227: 119-128. http://dx.doi.org/10.3141/2227-13

Wang, H.; Al-Qadi, I. L. 2009. Combined effect of moving wheel loading and three-dimensional contact stresses on perpetual pavement responses, Transportation Research Record 2095: 53-61. http://dx.doi.org/10.3141/2095-06

Zaabar, I.; Chatti, K. 2011. New mechanistic-empirical approach for estimating the effect of roughness on vehicle durability, Transportation Research Record 2227: 180-188. http://dx.doi.org/10.3141/2227-20

Zaabar, I.; Chatti, K. 2010. Identification of localized roughness features and their impact on vehicle durability, in HVTT11, International Heavy Vehicle Symposium: Balancing Competing Needs in Heavy Vehicle Transport Technology, 14-17 March 2010, Melbourne, Australia, 13 p. (CD).
Zhang, N.; Smith, W. A.; Jeyakumaran, J. 2010. Hydraulically interconnected vehicle suspension: background and modelling, Vehicle System Dynamics 48(1): 17-40.

http://dx.doi.org/10.1080/00423110903243182

Žuraulis, V.; Sokolovskij, E.; Matijošius, J. 2013. The opportunities for establishing the critical speed of the vehicle on research in its lateral dynamics, Eksploatacja $i$ Niezawodność - Maintenance and Reliability 15(4): 312-318. 